\title{
Effect of Interleukin-15 on CD11b, CD54, and CD62L Expression on Natural Killer Cell and Natural Killer T-Like Cells in Systemic Lupus Erythematosus
}

\author{
Syh-Jae Lin, ${ }^{1}$ Ji-Yih Chen, ${ }^{2}$ Ming-Ling Kuo, ${ }^{3,4,5}$ Hsiu-Shan Hsiao, \\ Pei-Tzu Lee, ${ }^{1}$ and Jing-Long Huang ${ }^{1}$ \\ ${ }^{1}$ Division of Asthma, Allergy, and Rheumatology, Department of Pediatrics, Chang Gung Children's Hospital, College of Medicine, \\ Chang Gung University, Taoyuan, Taiwan \\ ${ }^{2}$ Department of Medicine, Division of Allergy, Immunology and Rheumatology, Chang Gung Memorial Hospital, \\ Chang Gung University College of Medicine, Taiwan \\ ${ }^{3}$ Department of Microbiology and Immunology, Graduate Institute of Biomedical Sciences, College of Medicine, \\ Chang Gung University, Taoyuan, Taiwan \\ ${ }^{4}$ Division of Allergy, Asthma, and Rheumatology, Department of Pediatrics, Chang Gung Memorial Hospital, Taoyuan, Taiwan \\ ${ }^{5}$ Chang Gung Immunology Consortium, Chang Gung Memorial Hospital and Chang Gung University, Taoyuan, Taiwan
}

Correspondence should be addressed to Jing-Long Huang; long@adm.cgmh.org.tw

Received 28 July 2016; Accepted 4 October 2016

Academic Editor: Junhui Wang

Copyright (C) 2016 Syh-Jae Lin et al. This is an open access article distributed under the Creative Commons Attribution License, which permits unrestricted use, distribution, and reproduction in any medium, provided the original work is properly cited.

\begin{abstract}
Adhesion molecules may play an important role in systemic lupus erythematosus (SLE) pathogenesis. We investigated the effect of interleukin- (IL-) 15 on CD11b, CD54, and CD62L expression on natural killer (NK) cells, T cells, and CD56 ${ }^{+} \mathrm{CD}^{+}{ }^{+} \mathrm{NKT}$-like cells from SLE subjects and healthy controls. SLE patients had decreased circulating NK cells and NKT-like cells compared to controls. NK cells from SLE patients showed higher CD11b and CD62L expression compared to controls. IL-15 enhanced CD11b and CD54 but downregulated CD62L expression on NK cells from SLE patients. Similar observations were found for T cells and NKT-like cells. NK cells from SLE patients expressed higher CD56 than controls; both could be further enhanced by IL-15. IL-15 also enhanced CD56 expression of NKT-like cells from SLE patients. A greater degree of IL-15 induced downregulation of CD62L on NKT-like cells noted in SLE patients compared to controls. The percentage of CD1lb expressing NK cells and the \% inhibition of CD62L expression on NKT-like cells by IL-15 correlated with serum anti-dsDNA levels in SLE patients, respectively. Taken together, we demonstrated the dysfunctional NK and NKT-like cells in SLE patients with regard to CD11b and CD62L expression and their response to IL-15.
\end{abstract}

\section{Introduction}

Systemic lupus erythematosus (SLE) is characterized by many immunologic abnormalities involving various immune cells like T and B cells [1,2]. Natural killer (NK) cells, defined by expression of CD56 and lack of CD3, are important effector cells in the innate immune response against infections and tumors [3]. Two subsets of human peripheral blood NK cells have been identified: $\mathrm{CD} 56^{\mathrm{dim}} \mathrm{CD} 16^{+} \mathrm{NK}$ subset is more cytotoxic, while CD56 $6^{\text {bright }}$ subset has the capacity to produce abundant cytokines and plays an important immunoregulatory role [4]. Previous studies have found a decrease in NK cell numbers, impaired NK cytotoxicity, and defects of NK differentiation in SLE patients [5-8].

$\mathrm{CD}^{+}{ }^{+} \mathrm{CD} 56^{+}$NKT-like cells refer to a subset of $\alpha \beta$ $\mathrm{T}$ cells expressing NK activation receptors exhibiting an effector memory phenotype $[9,10]$. Like NK cells, NKTlike cells expand in response to viral infection by producing inflammatory cytokines, such as IFN- $\gamma$ [11]. Similar to NK cells, they possess antitumor activity and lyse target cells by secreting perforin and granzyme [12]. NKT-like cells were reported to be decreased in SLE patients. The number of 
NKT-like cells correlated inversely with SLE disease activity [13].

Interleukin- (IL-) 15 is a pleiotropic common gamma chain signaling cytokine that is important for the activation of $\mathrm{CD}^{+}{ }^{+} \mathrm{T}$ cells and NK cells $[14,15]$. IL-15 plays a crucial role in NK differentiation and survival, as in IL-15-deficient mice; the development of NK cells is severely compromised [16]. Patients with SLE have increased serum levels of IL-15, which did not correlate with disease severity $[17,18]$. It remains uncertain whether IL-15 may contribute to the pathogenesis of SLE.

Cell adhesion molecules that mediate the leukocyte recruitment to the inflamed tissue and regulate lymphocyte homing may play a pathogenic role in SLE $[19,20]$. CD1lb is an important integrin that marks NK cell maturation and cytotoxicity [21]. CD54 (ICAM-1) belongs to the immunoglobulin gene superfamily and plays an important role in various inflammatory conditions [22]. CD62L belongs to a member of selectins that is important for NK cells homing to the lymph nodes and also an important marker for NK maturation and response to viral infections [23]. Previous studies have shown that circulating soluble CD54 and CD62L correlated with SLE disease activity [24, 25].

In the present study we examined the expression of CD11b, CD54, and CD62L on NK, T, and NKT-like cells from the peripheral blood of both SLE patients and healthy controls. We sought to determine whether IL-15 would influence the expression of these molecules and their relationship to SLE disease activity.

\section{Materials and Methods}

2.1. Study Subjects. Study subjects include 33 SLE patients $(n=33)$ and 17 healthy controls recruited from Chang Gung Memorial Hospital (CGMH), Linkou, Taiwan. The diagnosis of SLE fulfills the 1997 American College of Rheumatology classification criteria [26]. We evaluated the severity of our SLE patients using the systemic lupus erythematosus disease activity index (SLEDAI) scoring method [27]. Laboratory parameters such as C3, C4, and anti-dsDNA were recorded. We obtained heparinized whole blood from each study individual under the preapproval by the institutional research committee at CGMH. Informed consent was provided for all blood donors.

2.2. PBMC Incubation. Peripheral blood mononuclear cells (PBMCs) were collected by Ficoll-Hypaque density gradient centrifugation (GE Healthcare, Uppsala, Sweden) within 6 hours of blood drawing. PBMCs were then incubated in RPMI-1640, 10\% fetal calf serum in the presence or absence of IL-15 at the concentration of $10 \mathrm{ng} / \mathrm{mL}$ (Peprotech, Rocky Hill, USA) for eighteen hours. NK cell viability remains $>98 \%$ after incubation with IL- 15 at $10 \mathrm{ng} / \mathrm{mL}$ for 18 hours, while IL15 at 50 or $100 \mathrm{ng} / \mathrm{mL}$ may induce the apoptosis of NK cells (data not shown).

2.3. Flow Cytometric Analysis. Following incubation with or without IL-15, PBMCs were harvested, washed, and resuspended for staining. For each experiment, cells were stained with APC-conjugated anti-CD3 antibody (BD Biosciences, San Jose, CA, USA), FITC-conjugated anti-CD56 antibody (BD Biosciences, San Jose, CA, USA), and PEconjugated anti-CD54, anti-CD11b, and anti-CD62L antibody (Beckman Coulter, Fullerton, CA, USA) for $30 \mathrm{~min}$ at $4^{\circ} \mathrm{C}$. Cells were then washed twice and analyzed by a Becton Dickinson FACScan analyzer. First, the lymphocyte population was gated to identify CD3-positive and CD3-negative lymphocyte populations. Secondly, the CD3-positive and CD3-negative lymphocyte populations were gated for further analysis of the expression patterns of CD56 and the adhesion molecules. In some experiments when NK cell numbers are adequate, $\mathrm{CD}_{56} 6^{+} \mathrm{CD} 3^{-} \mathrm{NK}$ cells were further divided by $\mathrm{CD} 16$ and CD56 staining in to 2 groups: $\mathrm{CD} 16^{+} \mathrm{CD} 56^{\mathrm{dim}}$ NK cells (more than $80 \%$ ) and CD16 ${ }^{\text {dim }}$ CD56 $6^{\text {bright }}$ NK cells according to the mean fluorescence intensity (MFIs) of CD56 (Figure 3 ). The \% inhibition of CD62L expression by IL-15 was calculated as [MFI of CD62L in medium - MFI of CD62L in the presence of IL-15 $(10 \mathrm{ng})$ for 18 hours/MFI of CD62L in medium] $\times 100$.

2.4. Statistics. The Wilcoxon signed rank test was applied for analysis of the responses before and after a treatment, using SPSS 9.0 software. The Mann-Whitney $U$ test was used to compare SLE and healthy donor responses. Spearman's rank correlation was applied to detect the association between different parameters. The data are presented as means \pm standard error of mean. Data were considered significantly different if $p$ was less than 0.05 .

\section{Results}

3.1. Patient Characteristics and Percentages of NK, T, and NKT-Like Cells. The characteristics of the controls and SLE patients were shown in Table 1. Patients were predominantly female, ages between 12 and 32 years, and had an average disease duration of $8.9 \pm 0.7$ years. Approximately $57.6 \%$ of patients were taking regular corticosteroids and some were receiving methotrexate, azathioprine, or mycophenolate. The percentages of $\mathrm{CD}^{+} 6^{+} \mathrm{CD}^{-}$NK cells from the peripheral blood of SLE patients were lower than those from healthy controls $(p=0.008)$. The percentages of $\mathrm{CD}^{2} 6^{+} \mathrm{CD}^{+}$NKTlike cells from SLE patients were also lower than controls $(p=0.038)$. There was no difference of the percentages of CD56 ${ }^{-} \mathrm{CD}^{+} \mathrm{T}$ cells between SLE patients and controls $(p=$ $0.38)$.

3.2. CD11b, CD54, and CD62L Expression on $C D 56^{+} \mathrm{CD}^{-}$ NK Cells. Figure 1(a) shows the CD11b, CD54, and CD62L expression on NK cells from SLE patients and controls. NK cells from SLE expressed higher CD1lb compared to controls ( $42.9 \pm 3.1 \%$ versus $31.0 \pm 5.1 \%, p=0.032$ ). The expression of CD54 on NK cells from SLE patients was not different from controls $(18.2 \pm 2.2 \%$ versus $14.3 \pm 2.5 \%, p=0.302)$. As the majority of NK, T, and NKT-like cells expressed CD62L (data not shown), CD62L expression was presented as MFI. The MFI of CD62L on NK cells from SLE patients was higher than controls (9226 \pm 1395 versus $5617 \pm 658, p=0.033$ ). 

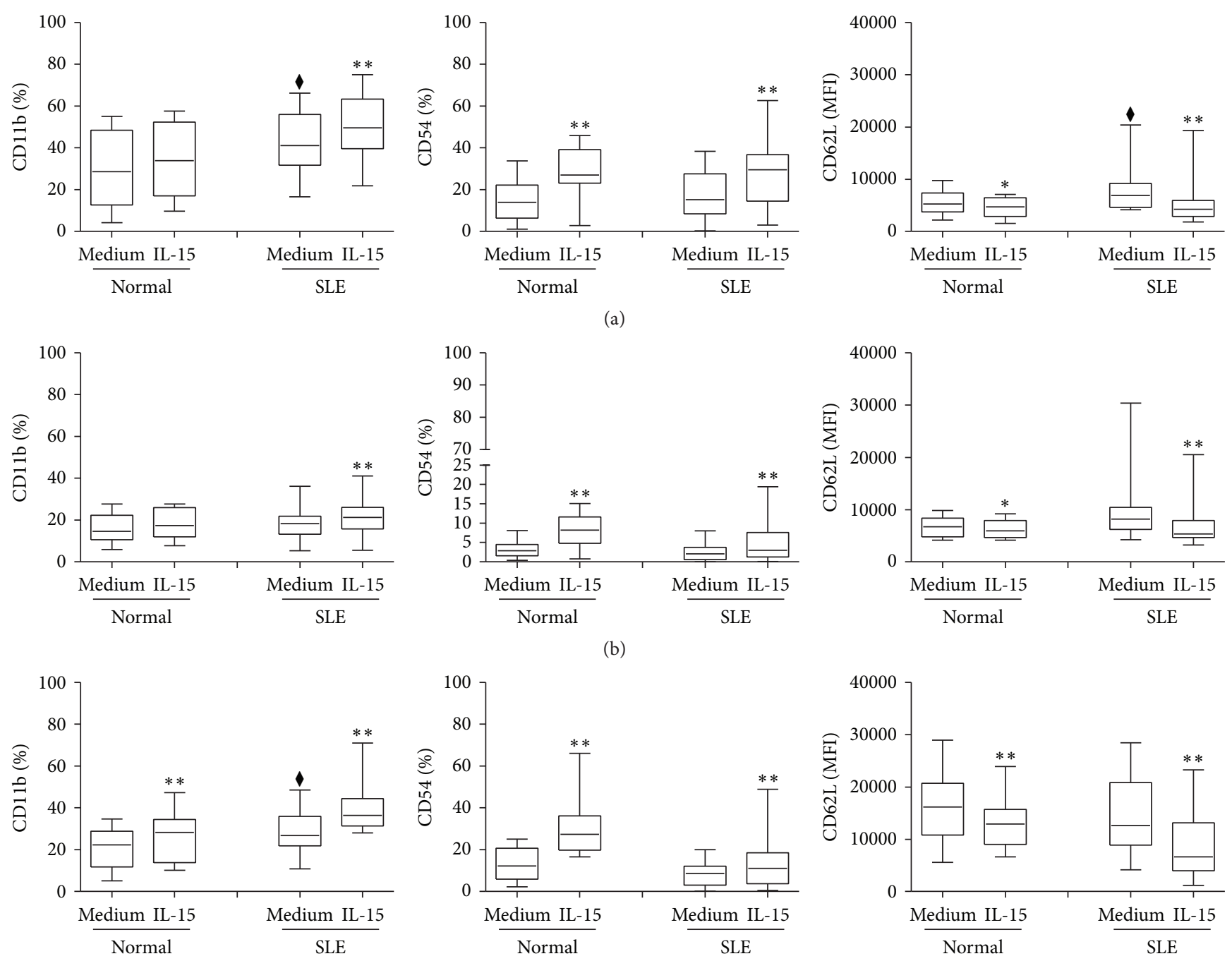

(c)

Figure 1: The CD11b, CD54, and CD62L expression on (a) $\mathrm{CD}_{6} 6^{+} \mathrm{CD}^{-} \mathrm{NK}$ cells, (b) $\mathrm{CD}^{-} 6^{-} \mathrm{CD}^{+} \mathrm{T}^{-}$cells, and (c) $\mathrm{CD}^{+} 6^{+} \mathrm{CD} 3^{+} \mathrm{NKT}^{-}$like cells from SLE patients and healthy controls. PBMCs were stimulated with IL-15 $(10 \mathrm{ng} / \mathrm{mL})$ for $18 \mathrm{hrs}$. Cells were stained by anti-CD3 and antiCD56 antibodies and segregated into $\mathrm{CD}_{5} 6^{+} \mathrm{CD}^{-} \mathrm{NK}$ cells, $\mathrm{CD} 56^{-} \mathrm{CD} 3^{+} \mathrm{T}$ cells, and $\mathrm{CD} 56^{+} \mathrm{CD} 3^{+} \mathrm{NKT}$-like cells. Surface marker $(\mathrm{CD} 11 \mathrm{~b}$, CD54, or CD62L) expression on each cell population was analyzed by flow cytometry. Data was expressed as percent expression (\%) \pm SEM. $p<0.05$ compared to normal; ${ }^{*} p<0.05 /{ }^{* *} p<0.01$ compared to medium (normal, $n=17$; SLE, $n=33$ ).

IL-15 enhanced the CD11b expression of NK cells from SLE patients $(50.1 \pm 2.9 \%$ versus $42.9 \pm 3.1 \%, p=0.012)$ but had no effect on CD11b expression of NK cells from controls $(34.8 \pm 4.9 \%$ versus $31.0 \pm 5.0 \%, p=0.055)$. IL-15 enhances the expression of CD54 on NK cells from both SLE patients $(27.4 \pm 2.8 \%$ versus $18.2 \pm 2.2 \%, p<0.001)$ and controls $(28.2 \pm 2.9 \%$ versus $14.3 \pm 2.5 \%, p=0.002)$, respectively. In contrast, IL-15 resulted in a decrease in CD62L expression on NK cells from both SLE patients $(5619 \pm 1357$ versus $9226 \pm$ $1395, p=0.028)$ and controls ( $4482 \pm 552$ versus $5617 \pm 658$, $p=0.001)$.

3.3. CD11b, CD54, and CD62L Expression on $C D 56 \mathrm{CD}^{+} \mathrm{T}$ Cells. CD11b, CD54, and CD62L expression on T cells from SLE patients and controls are shown in Figure 1(b). T cells expressed much lower CD11b and CD54 than did NK cells, both SLE patients and controls alike. T cells from SLE patients expressed comparable CD11b (17.9 $\pm 1.5 \%$ versus $16.1 \pm 1.9 \%$, $p=0.528), \operatorname{CD} 54(2.4 \pm 0.4 \%$ versus $3.3 \pm 0.6 \%, p=0.151)$, and CD62L $(65.7 \pm 3.1 \%$ versus $59.0 \pm 3.1 \%, p=0.193)$ compared to controls. IL-15 enhanced CD54 expression on $\mathrm{T}$ cells from SLE patients $(4.8 \pm 0.9 \%$ versus $2.4 \pm 0.4 \%, p<$ $0.001)$ and controls $(8.3 \pm 1.0 \%$ versus $3.3 \pm 0.6 \%, p=0.001)$ alike. IL-15 resulted in an increase of CD11b expression (20.7 $\pm 1.7 \%$ versus $17.9 \pm 1.5 \%, p=0.003)$ and a decrease of CD62L MFI $(7205.7 \pm 904.7$ versus $10767.9 \pm 1424.9, p<0.001)$ on $\mathrm{T}$ cells from SLE patients.

3.4. CD11b, CD54, and CD62L Expression on $C D 56^{+} C D 3^{+}$ NKT-Like Cells. CD11b, CD54, and CD62L expressions on NKT-like cells from SLE and controls are shown in Figure 1(c). NKT-like cells from SLE patients expressed higher 


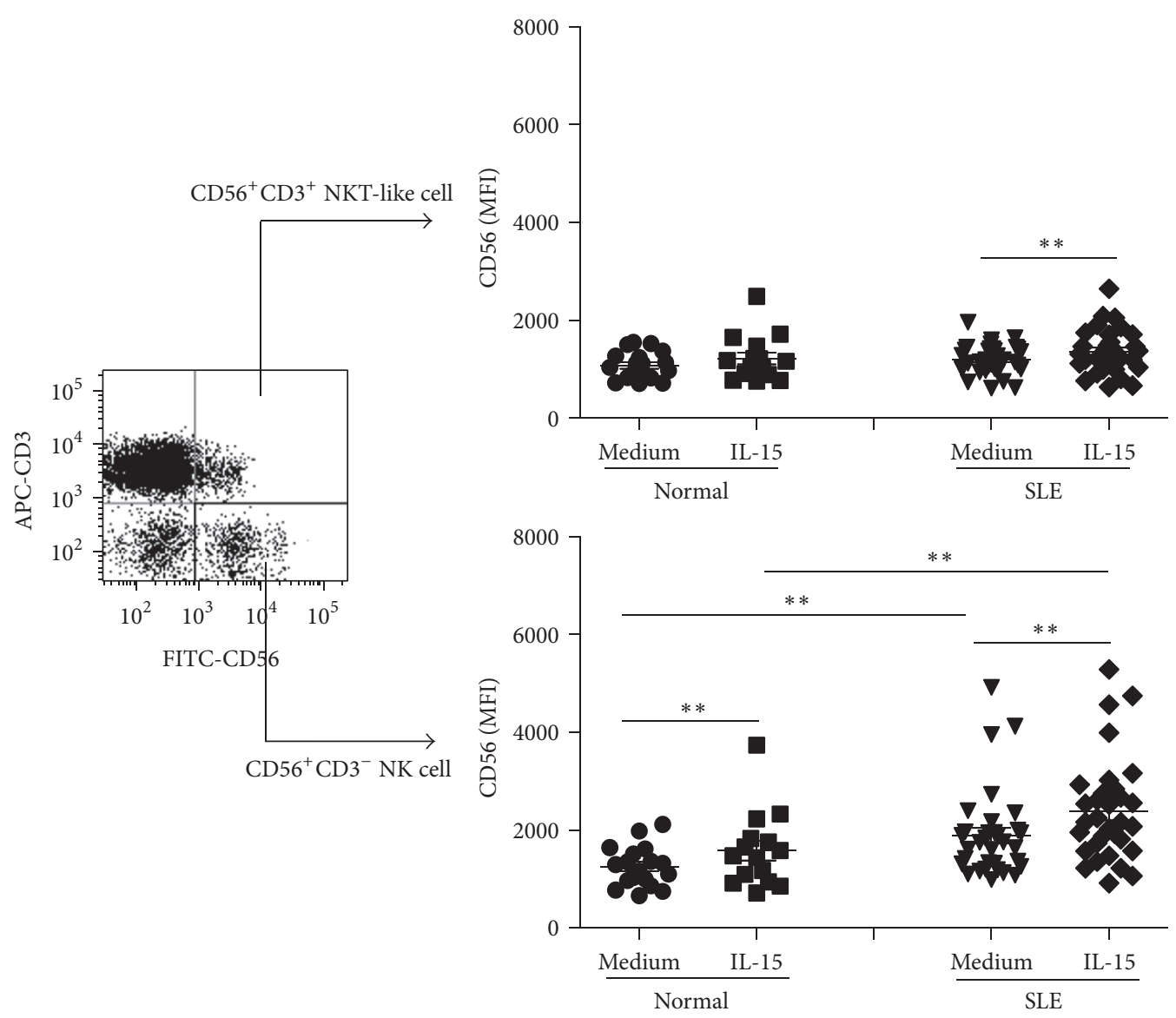

FIGURE 2: Effect of interleukin- (IL-) 15 on CD56 expression of $\mathrm{CD}^{+} 6^{+} \mathrm{CD} 3^{-} \mathrm{NK}$ cells and CD56 ${ }^{+} \mathrm{CD} 3^{+}$NKT-like cells from SLE patients and healthy controls. PBMCs were stimulated with IL-15 $(10 \mathrm{ng} / \mathrm{mL})$ for $18 \mathrm{hrs}$ and stained with anti-CD3 and anti-CD56. The CD56 ${ }^{+} \mathrm{CD}^{-}$ $\mathrm{NK}$ and $\mathrm{CD}_{5} 6^{+} \mathrm{CD}^{+} \mathrm{NKT}$-like cell population were separated by flow cytometry as illustrated. Data was expressed as mean fluorescence intensity (MFI) \pm SEM. ${ }^{* *} p<0.01$ (normal, $n=17$; SLE, $n=33$ ).

CD11b $(28.7 \pm 1.9 \%$ versus $21.0 \pm 2.7 \%, p=0.043)$ but comparable CD54 ( $8.5 \pm 1.2 \%$ versus $13.2 \pm 2.5 \%, p=0.075)$ and CD62L (14565 \pm 1392 versus $16676 \pm 1630[\mathrm{MFI}], p=$ $0.317)$ compared to controls. Similar to that observed in NK cells, IL-15 enhanced CD11b and CD54 expression on NKTlike cells from both SLE patients (CD11b: $38.4 \pm 1.9 \%$ versus $28.7 \pm 1.9 \%, p<0.001$; CD54: $14.5 \pm 2.9 \%$ versus $8.5 \pm 1.2 \%$, $p=0.005$ ) and controls (CD11b: $26.0 \pm 3.1 \%$ versus 21.0 $\pm 2.7 \%, p=0.007$; CD54: $30.6 \pm 4.2 \%$ versus $13.2 \pm 2.5 \%$, $p=0.007)$, respectively. IL-15 resulted in a decrease in CD62L MFI on NKT-like cells from both SLE patients $(9213 \pm 1150$ versus $14565 \pm 1392, p<0.001)$ and controls $(13151 \pm 1214$ MFI versus $16676 \pm 1630, p=0.002)$.

3.5. IL-15 Enhances CD56 Expression on NK and NKT-Like Cells from SLE. We next examine the expression of CD56, another NK marker responsible for adhesive function [28], on NK cells from SLE patients compared to controls. As shown in Figure 2, although NK cells are deficient in numbers compared to controls (Table 1), NK cells from SLE patients exhibited higher CD56 MFI on $\mathrm{CD}^{-} \mathrm{CD}^{-} 6^{+} \mathrm{NK}$ cells (1886.4 \pm 156.7 versus $1250.9 \pm 96.8, p=0.002)$. IL-15 enhanced
CD56 MFI on NK cells from both SLE patients and controls. The CD56 MFI on NKT-like cells from SLE patients was comparable to that from controls. IL-15 enhanced CD56 MFI of NKT-like cells from SLE patients $(1363 \pm 79$ versus $1199 \pm$ $52, p=0.001)$ and had no effect on controls (1218 \pm 120 versus $1079 \pm 67, p=0.211$ ).

3.6. CD56 $6^{\text {bright }} \mathrm{NK}$ Cells Were More Responsive to IL-15 Induced Downregulation of CD62L. When NK cells are further divided into $\mathrm{CD} 56^{\text {bright }} \mathrm{CD} 16^{-}$and $\mathrm{CD} 56{ }^{\mathrm{dim}} \mathrm{CD} 16^{+}$ subsets (Figure 3), we found that there is no difference of CD11b, CD54, and CD62L expression between CD56 ${ }^{\text {bright }}$ and CD56 ${ }^{\mathrm{dim}} \mathrm{NK}$ cell subsets in SLE patients and controls alike. For SLE patients, IL-15 enhanced CD11b expression of CD56 ${ }^{\text {bright }} \mathrm{NK}$ subsets $(58.8 \pm 4.2 \%$ versus $50.4 \pm 4.9 \%, p=$ $0.002)$ but did not affect that of the CD56 ${ }^{\mathrm{dim}}$ subsets $(52.1 \pm$ $4.2 \%$ versus $47.8 \pm 4.6 \%, p=0.096)$. No significant difference of CD54 expression and its response to IL-15 was noted between CD56 ${ }^{\text {bright }}$ and CD $56^{\text {dim }} \mathrm{NK}$ subsets. CD56 ${ }^{\text {bright }} \mathrm{NK}$ cells expressed greater CD62L than did CD56 ${ }^{\text {dim }}$ subsets. IL-15 downregulates CD62L expression on CD56 ${ }^{\text {bright }} \mathrm{NK}$ 


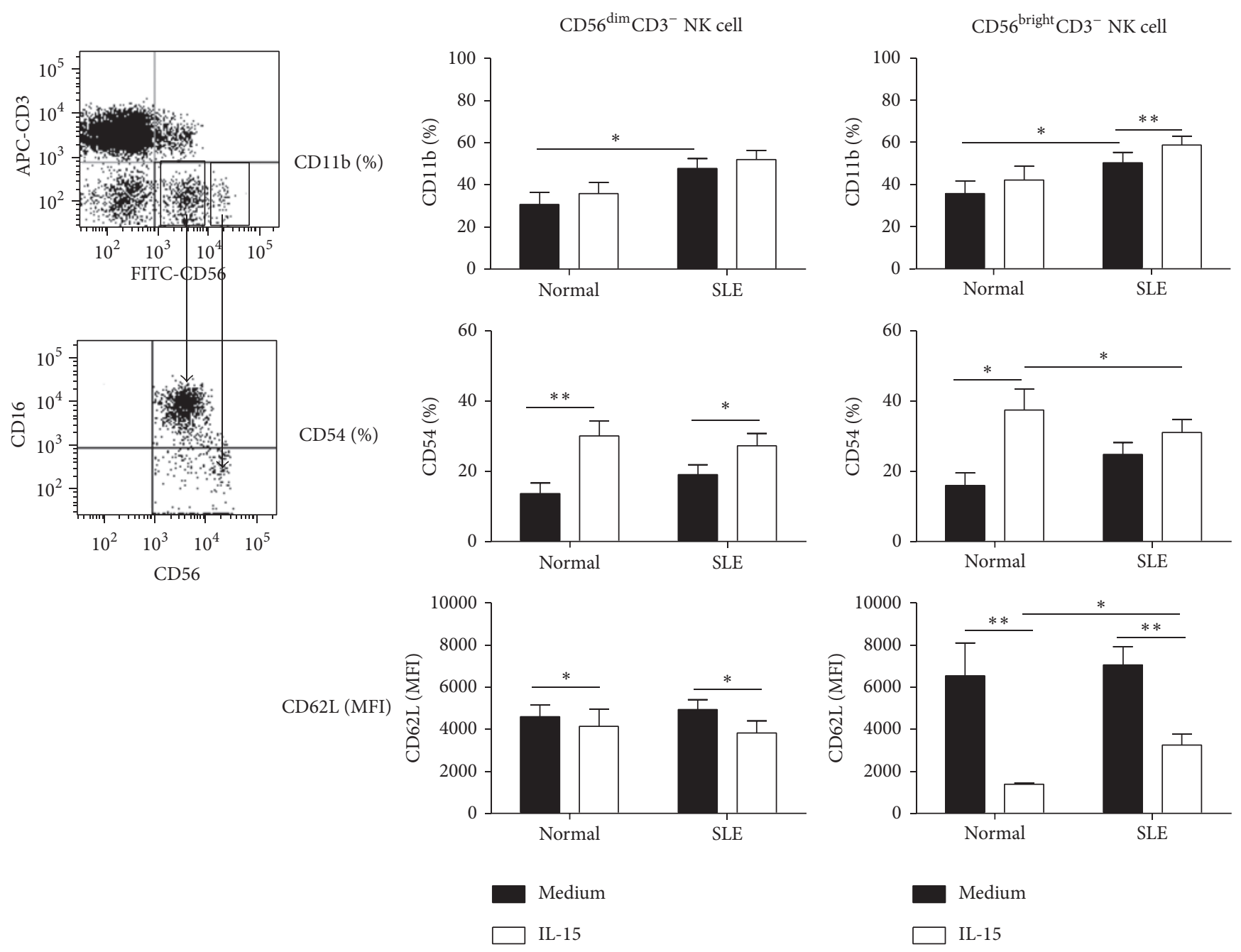

Figure 3: The CD11b, CD54, and CD62L expression on CD56 ${ }^{\mathrm{dim}} \mathrm{CD}^{-}$and CD56 ${ }^{\text {bright }} \mathrm{CD} 3^{-} \mathrm{NK}$ cells from SLE and healthy donors. PBMCs were stimulated with IL-15 (10 ng/mL) for $18 \mathrm{hrs}$ and stained with anti-CD3 and anti-CD56. A representative profile of how the CD56 $6^{\mathrm{dim}}$ and CD56 ${ }^{\text {bright }}$ NK populations were gated under flow cytometry is shown. Data was expressed as percent expression $(\%) \pm$ SEM. ${ }^{*} p<0.05$ and ${ }^{* *} p<0.01$ (normal, $n=10$; SLE, $n=17$ ).

subsets to a greater extent than on that of on CD56 ${ }^{\mathrm{dim}}$ subsets from SLE patients $(28.3 \pm 4.7 \%$ versus $20.6 \pm 3.4 \%, p=$ $0.023)$.

3.7. Greater CD62L Downregulation by IL-15 in NKT-Like Cells from SLE Patients. We next compare the degree of CD62L inhibition by IL-15 of NK cells and NKT-like cells (Figure 4). The \% downregulation of CD62L MFI by IL-15 in NK cells was comparable between SLE patients and controls $(21.3 \pm 3.3 \%$ versus $23.8 \pm 4.4 \%, p=0.66)$. However, NKTlike cells from SLE were more susceptible to IL-15 induced downregulation compared to controls $(22.4 \pm 5.2 \%$ versus 8.4 $\pm 2.5 \%, p=0.018$ )

3.8. Correlation of CD11b and CD62L Expression on NK and NKT Cells and Disease Activity. To evaluate the clinical relevance of adhesion molecule expression on NK and NKTlike cells in SLE patients, we investigate relationships of the percentages of NK and NKT-like cell bearing CD1lb and CD62L and SLE-related laboratory parameters by regression analysis. As shown in Figure 5, univariate analysis showed that the percentages of $\mathrm{CD} \mathrm{b}^{+} \mathrm{NK}$ cells correlated with serum anti-dsDNA levels, in SLE patients $(r=0.428, p=$ 0.041 ), while the \% inhibition of CD62L MFI by IL-15 of NKT-like cells also correlates with serum anti-ds DNA levels $(r=0.374, p=0.043)$.

\section{Discussion}

In the present study, we compared the expression of adhesion molecules CD11b, CD54, and CD62L on NK, T, and NKT-like cells from SLE patients and healthy controls. We also determined the effect of IL-15, an immunoregulatory cytokine, on adhesion molecule expression. IL-15 may directly affect immune cells or indirectly by upregulating other inflammatory mediators. We have shown that IL-15 could enhance 
TABLE 1: Characteristics of controls and patients with SLE.

\begin{tabular}{|c|c|c|}
\hline Characteristics & Controls $(n=17)$ & $\begin{array}{l}\text { SLE patients } \\
\quad(n=33)\end{array}$ \\
\hline Sex (male/female) & $0 / 17$ & $0 / 33$ \\
\hline Age, mean (range) & $29.3 \pm 0.9(27-34)$ & $\begin{array}{c}22.5 \pm 0.9 \\
(12-32)\end{array}$ \\
\hline $\begin{array}{l}\text { SLEDAI score, median } \\
\text { (range) }\end{array}$ & NA & $7(0 \sim 25)$ \\
\hline C3, median (range) & NA & $66.7(21-106)$ \\
\hline C4, median (range) & NA & $9.7(2.1-32.9)$ \\
\hline $\begin{array}{l}\text { Anti-dsDNA, median } \\
\text { (range) }\end{array}$ & NA & $\begin{array}{c}309.9 \\
(79.6-632.8)\end{array}$ \\
\hline Average disease duration & NA & $8.9 \pm 0.7$ \\
\hline $\begin{array}{l}\text { Taking regular } \\
\text { corticosteroids }\end{array}$ & NA & $57.6 \%$ \\
\hline \multicolumn{3}{|l|}{ Cell population } \\
\hline $\begin{array}{l}\mathrm{CD}^{+} 6^{+} \mathrm{CD}^{-} \mathrm{NK} \text { cells } \\
(\%)^{\#}\end{array}$ & $7.3 \pm 0.9 \%$ & $4.4 \pm 0.6 \%^{* *}$ \\
\hline $\mathrm{CD}^{2} 6^{-} \mathrm{CD} 3^{+} \mathrm{T}$ cells $(\%)$ & $71.8 \pm 1.4 \%$ & $67.2 \pm 2.8 \%$ \\
\hline $\begin{array}{l}\mathrm{CD} 56^{+} \mathrm{CD}^{+} \text {NKT-like } \\
\text { cells }(\%)\end{array}$ & $3.5 \pm 0.6 \%$ & $2.2 \pm 0.3 \%^{*}$ \\
\hline
\end{tabular}

${ }^{*} p<0.05$ and ${ }^{* *} p<0.01$ compared to controls; ${ }^{\#}$ the percentages of NK cells, T cells, and NKT-like cells in total lymphocytes.

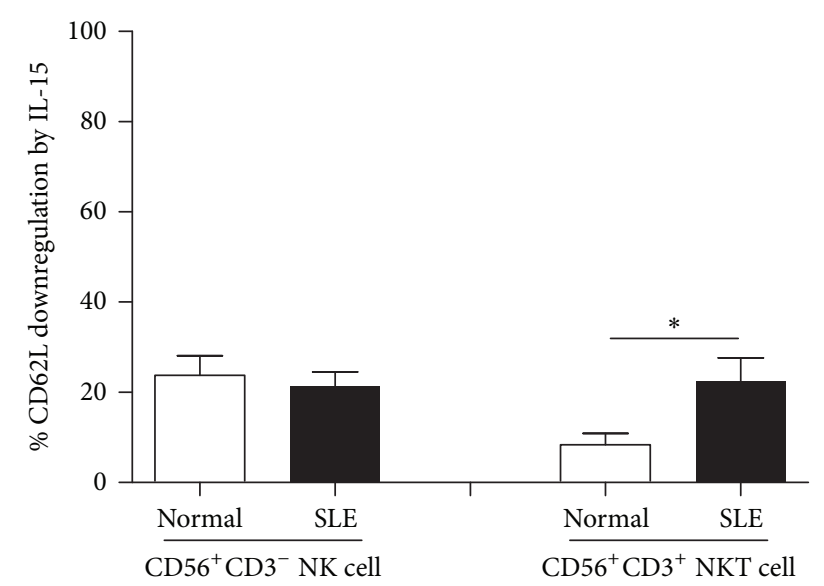

Figure 4: The inhibition of CD62L expression by IL-15 on $\mathrm{CD} 6^{+} \mathrm{CD}^{-} \mathrm{NK}$ cells and $\mathrm{CD} 56^{+} \mathrm{CD}^{+}{ }^{+}$NKT-like cells from SLE and healthy donors. PBMCs were stained with anti-CD3, antiCD56, and anti-CD62L antibodies and were analyzed under flow cytometry. \% CD62L downregulation by IL-15 is calculated as [MFI of CD62L in medium - MFI of CD62L in the presence of IL-15 $(10 \mathrm{ng} / \mathrm{mL})$ for 18 hours/MFI of CD62L in medium] $\times 100 .{ }^{*} p<0.05$ (normal, $n=10$; SLE, $n=17$ ).

tumor necrosis factor-alpha and interferon-gamma production of NK cells [29]. We have also demonstrated that IL15 induced interferon-gamma but not IL-4 production from human iNKT cells [30].

In agreement with the previous studies $[31,32]$, we found that the percentages of NK cells and NKT-like cells are decreased in PBMC from SLE patients compared to controls.
However, The percentages of $\mathrm{T}$ cells were comparable to controls. CD11b, but not CD54 and CD62L expression on NK cells from SLE patients, was increased compared to controls. NK cells progress from an immature $\mathrm{CD} 27^{+} \mathrm{CD} 11 \mathrm{~b}^{-}$ stage to an intermediate $\mathrm{CD} 27^{+} \mathrm{CD} 11 \mathrm{~b}^{+}$stage and finally to a $\mathrm{CD}^{-} 7^{-} \mathrm{CD} 11 \mathrm{~b}^{+}$stage [33]. $\mathrm{CD} 11 \mathrm{~b}^{+} \mathrm{NK}$ cells are more readily responsive to cytokine-mediated activation during viral infection [34]. Our findings suggest that $\mathrm{CD}_{11 \mathrm{~b}^{+}}$bearing NK cells may play a pathogenic role in SLE.

$\mathrm{T}$ cells from SLE have been shown to have aberrant signaling, abnormal cytokine secretion [35]; we found however that CD11b, CD54, and CD62L expression of T cells from SLE was comparable to controls. $\mathrm{CD}^{+}{ }^{+} \mathrm{CD} 56^{+}$NKT-like cells have been reported to be increased in certain autoimmune conditions like Behçet's diseases [36, 37]. Similar to that observed with NK cells, we found that $\mathrm{CD} 3^{+} \mathrm{CD} 56^{+}$NKT-like cells from SLE patients exhibited higher CD11b expression compared to the corresponding controls.

Consistent with our previous work [38, 39], IL-15 enhanced CD54 expression of NK, T, and NKT-like cells from SLE patients and controls alike, suggesting its ability to promote cell migration and cytotoxicity. We found that IL15 enhanced CD1lb expression of NK cells and T cells from SLE patients, respectively, an effect not observed with healthy controls. Contrary to that observed in CD11b and CD54, we found that IL-15 downregulates CD62L expression on NKT cells and NKT-like cells, from SLE patients and controls.

Although the percentages of NK cells decreased, we found that the CD56 MFI was elevated on SLE NK cells compared to controls, consistent with Schepis et al. [7]. We further demonstrated that CD56 expression on NK cells from SLE patients could be further enhanced with IL-15 stimulation. IL15 also preferentially enhanced MFI of CD56 of NKT-like cells from SLE patients. Thus, IL-15 may play a disease-promoting role by enhancing CD56 expression on NK and NKT-like cells of SLE patients.

Previous studies have shown the dysregulation of CD56 ${ }^{\text {bright }} \mathrm{NK}$ cells in SLE patients [7, 31]. We found that CD56 ${ }^{\text {bright }} \mathrm{NK}$ cells from SLE patients expressed higher CD11b and CD62L than the CD56 ${ }^{\text {dim }}$ counterparts. CD11b on CD56 ${ }^{\text {bright }} \mathrm{NK}$ cells from SLE patients but not controls could be enhanced by IL-15. CD $56^{\text {bright }}$ NK cells were also more readily susceptible to IL-15 compared to their CD56 ${ }^{\mathrm{dim}}$ counterparts with regard to CD62L downregulation.

There was no difference in the \% inhibition of CD62L by IL-15 on NK cells between SLE patients and controls. However, a greater degree of IL-15 induced downregulation of CD62L on NKT-like cells was noted in SLE patients compared to controls. IL-15 resulted in shedding of CD62L on NK cells and especially NKT-like cells to the circulation which may aggravate the tissue inflammation in SLE. Serum soluble CD62L has been reported to be an SLE disease marker [40, 41].

Correlation analysis revealed that CD11b expression on NK cells correlated with serum anti-dsDNA levels in SLE patients. The $\%$ inhibition of CD62L MFI by IL-15 of NKTlike cells also correlated with serum anti-dsDNA levels. IL-15 


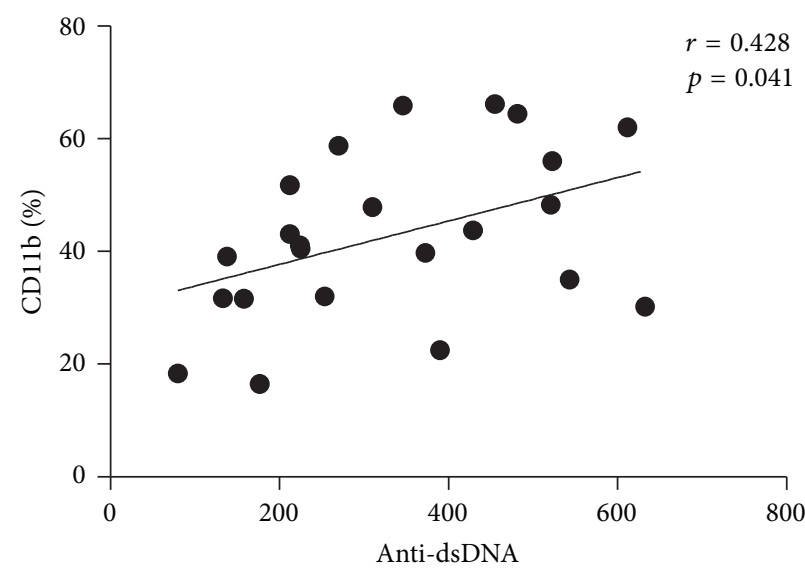

(a)

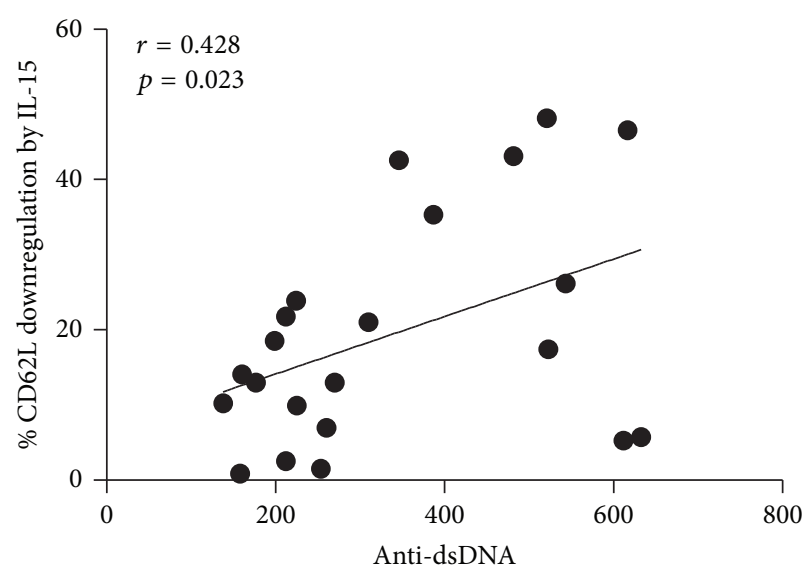

(b)

FIGURE 5: Correlation between (a) serum anti-dsDNA and the percentages of CD11b ${ }^{+} \mathrm{NK}$ cells and (b) serum anti-dsDNA and the $\%$ inhibition of CD62L MFI on NKT-like cells by IL-15 calculated as [MFI of CD62L in medium - MFI of CD62L in the presence of IL-15 (10 ng/mL) for 18 hours/MFI of CD62L in medium] $\times 100$.

may aggravate SLE disease severity by promoting CD62L shedding from the surface of NKT-like cells.

Cytokine inhibition may be used as a strategy for treating SLE. Ma et al. demonstrated a beneficial effect of anti-IL15 in the treatment of murine lupus [42]. Humax-IL15, a human IgG1 anti-IL-15 monoclonal antibody, has been shown to improve symptoms in patients with rheumatoid arthritis [43]. Our finding suggests that IL-15 may be a potential target for immunotherapy against SLE.

Taken together, we demonstrated the dysfunctional NK and NKT-like cells in SLE patients with regard to CD11b and CD62L expressions and their response to IL-15. IL-15 may aggravate inflammation by preferentially upregulating CD11b and CD56 and downregulating CD62L on NK and NKTlike cells in SLE patients. Antagonist to IL-15 may provide a therapeutic option to ameliorate the progression of SLE.

\section{Competing Interests}

The authors declare that they have no competing interests.

\section{Acknowledgments}

This study was supported partially by grants from National Science Council of Republic of China: MOST103-2314B-182A-023-MY3. It was also supported by Division of Asthma, Allergy, and Rheumatology, Department of Pediatrics, Chang Gung Children's Hospital: CMRPG4A0052 and CMRPG3D1933.

\section{References}

[1] Y. Renaudineau, J.-O. Pers, B. Bendaoud, C. Jamin, and P. Youinou, "Dysfunctional B cells in systemic lupus erythematosus," Autoimmunity Reviews, vol. 3, no. 7-8, pp. 516-523, 2004.

[2] M. Miyara, Z. Amoura, C. Parizot et al., "Global natural regulatory T cell depletion in active systemic lupus erythematosus," The Journal of Immunology, vol. 175, no. 12, pp. 8392-8400, 2005.
[3] M. A. Cooper, T. A. Fehniger, and M. A. Caligiuri, "The biology of human natural killer-cell subsets," Trends in Immunology, vol. 22, no. 11, pp. 633-640, 2001.

[4] M. A. Cooper, T. A. Fehniger, S. C. Turner et al., "Human natural killer cells: a unique innate immunoregulatory role for the CD56 ${ }^{\text {bright }}$ subset," Blood, vol. 97, no. 10, pp. 3146-3151, 2001.

[5] M. R. J. Green, A. S. M. Kennell, M. J. Larche, M. H. Seifert, D. A. Isenberg, and M. R. Salaman, "Natural killer cell activity in families of patients with systemic lupus erythematosus: demonstration of a killing defect in patients," Clinical and Experimental Immunology, vol. 141, no. 1, pp. 165-173, 2005.

[6] A. Yabuhara, F.-C. Yang, T. Nakazawa et al., "A killing defect of natural killer cells as an underlying immunologic abnormality in childhood systemic lupus erythematosus," The Journal of Rheumatology, vol. 23, no. 1, pp. 171-177, 1996.

[7] D. Schepis, I. Gunnarsson, M.-L. Eloranta et al., "Increased proportion of CD56bright natural killer cells in active and inactive systemic lupus erythematosus," Immunology, vol. 126, no. 1, pp. 140-146, 2009.

[8] B. Hervier, V. Beziat, J. Haroche et al., "Phenotype and function of natural killer cells in systemic lupus erythematosus: excess interferon- $\gamma$ production in patients with active disease," Arthritis and Rheumatism, vol. 63, no. 6, pp. 1698-1706, 2011.

[9] D. I. Godfrey, H. R. MacDonald, M. Kronenberg, M. J. Smyth, and L. Van Kaer, "NKT cells: what's in a name?" Nature Reviews Immunology, vol. 4, no. 3, pp. 231-237, 2004.

[10] M. Giroux and F. Denis, "CD1d-unrestricted human NKT cells release chemokines upon Fas engagement," Blood, vol. 105, no. 2, pp. 703-710, 2005.

[11] P. Kokordelis, B. Krämer, C. Boesecke et al., "CD3(+)CD56(+) natural killer-like $\mathrm{T}$ cells display anti-HCV activity but are functionally impaired in $\operatorname{HIV}(+)$ Patients with acute hepatitis C," Journal of Acquired Immune Deficiency Syndromes, vol. 70, no. 4, pp. 338-346, 2015.

[12] A. Bojarska-Junak, I. Hus, M. Sieklucka et al., "Natural killer-like T CD3+/CD16+CD56+ cells in chronic lymphocytic leukemia: intracellular cytokine expression and relationship with clinical outcome," Oncology Reports, vol. 24, no. 3, pp. 803$810,2010$. 
[13] M. R. J. Green, A. S. M. Kennell, M. J. Larche, M. H. Seifert, D. A. Isenberg, and M. R. Salaman, "Natural killer T cells in families of patients with systemic lupus erythematosus: their possible role in regulation of IgG production," Arthritis and Rheumatism, vol. 56, no. 1, pp. 303-310, 2007.

[14] K. H. Grabstein, J. Eisenman, K. Shanebeck et al., "Cloning of a $\mathrm{T}$ cell growth factor that interacts with the $\beta$ chain of the interleukin-2 receptor," Science, vol. 264, no. 5161, pp. 965-968, 1994.

[15] J. G. Giri, D. M. Anderson, S. Kumaki, L. S. Park, K. H. Grabstein, and D. Cosman, "IL-15, a novel T cell growth factor that shares activities and receptor components with IL-2," Journal of Leukocyte Biology, vol. 57, no. 5, pp. 763-766, 1995.

[16] M. K. Kennedy, M. Glaccum, S. N. Brown et al., "Reversible defects in natural killer and memory CD8 $\mathrm{T}$ cell lineages in interleukin 15-deficient mice," The Journal of Experimental Medicine, vol. 191, no. 5, pp. 771-780, 2000.

[17] L. Baranda, H. de la Fuente, E. Layseca-Espinosa et al., "IL15 and IL-15R in leucocytes from patients with systemic lupus erythematosus," Rheumatology, vol. 44, no. 12, pp. 1507-1513, 2005.

[18] M. Aringer, G. H. Stummvoll, G. Steiner et al., "Serum interleukin-15 is elevated in systemic lupus erythematosus," Rheumatology, vol. 40, no. 8, pp. 876-881, 2001.

[19] T. Wais, W. Fierz, T. Stoll, and P. M. Villiger, "Subclinical disease activity in systemic lupus erythematosus: immunoinflammatory markers do not normalize in clinical remission," The Journal of Rheumatology, vol. 30, no. 10, pp. 2133-2139, 2003.

[20] P. Horák, V. Ščudla, Z. Heřmanová et al., "Clinical utility of selected disease activity markers in patients with systemic lupus erythematosus," Clinical Rheumatology, vol. 20, no. 5, pp. 337344, 2001.

[21] B. Fu, Z. Tian, and H. Wei, "Subsets of human natural killer cells and their regulatory effects," Immunology, vol. 141, no. 4, pp. 483-489, 2014.

[22] T. Zimmerman and F. J. Blanco, "Inhibitors targeting the LFA1/ICAM-1 cell-adhesion interaction: design and mechanism of action," Current Pharmaceutical Design, vol. 14, no. 22, pp. 21282139, 2008.

[23] H. Peng, R. Sun, L. Tang, H. Wei, and Z. Tian, "CD62L is critical for maturation and accumulation of murine hepatic NK cells in response to viral infection," The Journal of Immunology, vol. 190, no. 8, pp. 4255-4262, 2013.

[24] A. I. Russell, D. S. C. Graham, S. Chadha et al., "No association between E- and L-selectin genes and SLE: soluble L-selectin levels do correlate with genotype and a subset in SLE," Genes and Immunity, vol. 6, no. 5, pp. 422-429, 2005.

[25] T. K. Tso and W.-N. Huang, "Elevated soluble intercellular adhesion molecule-1 levels in patients with systemic lupus erythematosus: relation to insulin resistance," The Journal of Rheumatology, vol. 34, no. 4, pp. 726-730, 2007.

[26] M. Petri, "Review of classification criteria for systemic lupus erythematosus," Rheumatic Disease Clinics of North America, vol. 31, no. 2, pp. 245-254, 2005.

[27] C. Bombardier, D. D. Gladman, M. B. Urowitz, D. Caron, and C. H. Chang, "Derivation of the SLEDAI. A disease activity index for lupus patients. The Committee on Prognosis Studies in SLE," Arthritis and Rheumatology, vol. 35, no. 6, pp. 630-640, 1992.

[28] T. Michel, A. Poli, A. Cuapio et al., "Human CD56bright NK cells: an update," The Journal of Immunology, vol. 196, no. 7, pp. 2923-2931, 2016.
[29] S.-J. Lin, P.-J. Cheng, T.-Y. Lin, P.-T. Lee, H.-S. Hsiao, and M.-L. Kuo, "Effect of influenza A infection on umbilical cord blood natural killer function regulation with interleukin-15," Journal of Infectious Diseases, vol. 205, no. 5, pp. 745-756, 2012.

[30] S.-J. Lin, Y.-C. Huang, P.-J. Cheng, P.-T. Lee, H.-S. Hsiao, and M.-L. Kuo, "Interleukin-15 enhances the expansion and function of natural killer $\mathrm{T}$ cells from adult peripheral and umbilical cord blood," Cytokine, vol. 76, no. 2, pp. 348-355, 2015.

[31] A. Henriques, L. Teixeira, L. Inês et al., "NK cells dysfunction in systemic lupus erythematosus: relation to disease activity," Clinical Rheumatology, vol. 32, no. 6, pp. 805-813, 2013.

[32] F. M. Erkeller-Yuksel, P. M. Lydyard, and D. A. Isenberg, "Lack of NK cells in lupus patients with renal involvement," Lupus, vol. 6, no. 9, pp. 708-712, 1997.

[33] Y. Hayakawa and M. J. Smyth, "CD27 dissects mature NK cells into two subsets with distinct responsiveness and migratory capacity," The Journal of Immunology, vol. 176, no. 3, pp. 15171524, 2006.

[34] B. E. Freeman, H.-P. Raué, A. B. Hill, and M. K. Slifka, "Cytokine-mediated activation of NK cells during viral infection," Journal of Virology, vol. 89, no. 15, pp. 7922-7931, 2015.

[35] D. Comte, M. P. Karampetsou, and G. C. Tsokos, "T cells as a therapeutic target in SLE," Lupus, vol. 24, no. 4-5, pp. 351-363, 2015.

[36] J. K. Ahn, H. Chung, D.-S. Lee, Y. S. Yu, and H. G. Yu, "CD $8{ }^{\text {bright }} \mathrm{CD} 566^{+} \mathrm{T}$ cells are cytotoxic effectors in patients with active Behçet's uveitis," The Journal of Immunology, vol. 175, no. 9, pp. 6133-6142, 2005.

[37] J. K. Ahn, J.-M. Seo, J. Yu, F. S. Oh, H. Chung, and H. G. Yu, "Down-regulation of IFN- $\gamma$-producing CD56+ T cells after combined low-dose cyclosporine/prednisone treatment in patients with Behçet's uveitis," Investigative Ophthalmology and Visual Science, vol. 46, no. 7, pp. 2458-2464, 2005.

[38] S.-J. Lin and M.-L. Kuo, "Effect of cyclosporin A on interleukin15-activated umbilical cord blood natural killer cell function," Cytotherapy, vol. 10, no. 4, pp. 397-405, 2008.

[39] S.-J. Lin and D.-C. Yan, "ICAM-1 (CD54) expression on T lymphocytes and natural killer cells from umbilical cord blood: regulation with interleukin-12 and interleukin-15," Cytokines, Cellular and Molecular Therapy, vol. 6, no. 4, pp. 161-164, 2000.

[40] P. P. Sfikakis, D. Charalambopoulos, G. Vaiopoulos, and M. Mavrikakis, "Circulating P- and L-selectin and T-lymphocyte activation in patients with autoimmune rheumatic diseases," Clinical Rheumatology, vol. 18, no. 1, pp. 28-32, 1999.

[41] J. Font, P. Pizcueta, M. Ramos-Casals et al., "Increased serum levels of soluble L-selectin (CD62L) in patients with active systemic lupus erythematosus (SLE)," Clinical and Experimental Immunology, vol. 119, no. 1, pp. 169-174, 2000.

[42] N. Ma, H. Xiao, B. Marrero et al., "Combination of TACI-IgG and anti-IL-15 treats murine lupus by reducing mature and memory B cells," Cellular Immunology, vol. 289, no. 1-2, pp. 140144, 2014.

[43] B. Baslund, N. Tvede, B. Danneskiold-Samsoe et al., "Targeting interleukin-15 in patients with rheumatoid arthritis: A Proofof-Concept Study," Arthritis \& Rheumatism, vol. 52, no. 9, pp. 2686-2692, 2005. 


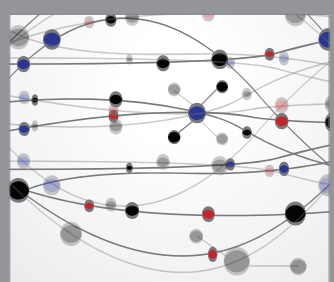

The Scientific World Journal
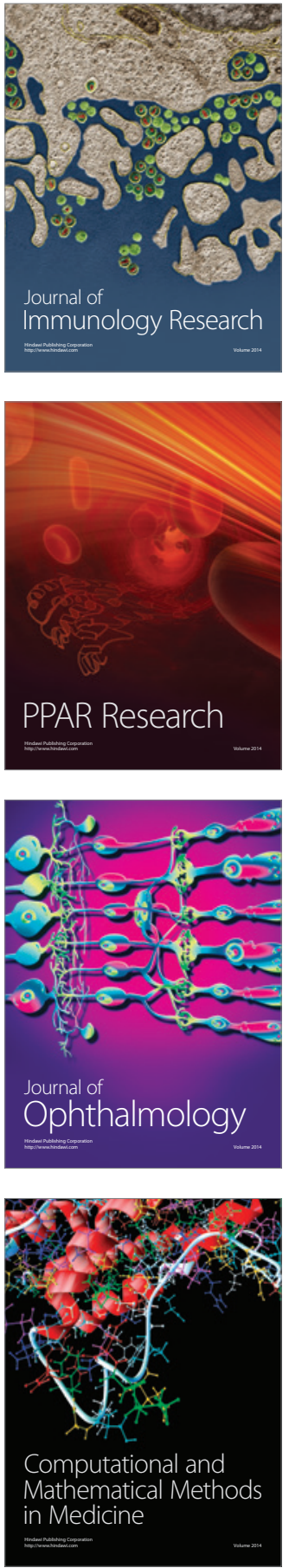

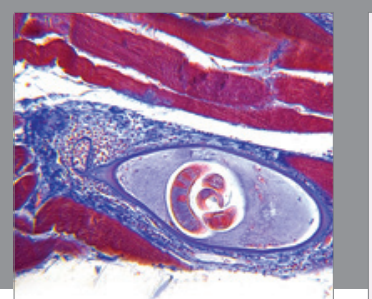

Gastroenterology Research and Practice

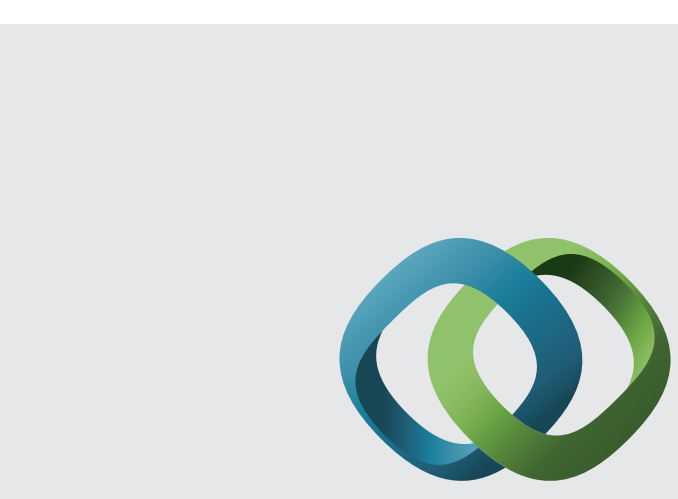

\section{Hindawi}

Submit your manuscripts at

http://www.hindawi.com
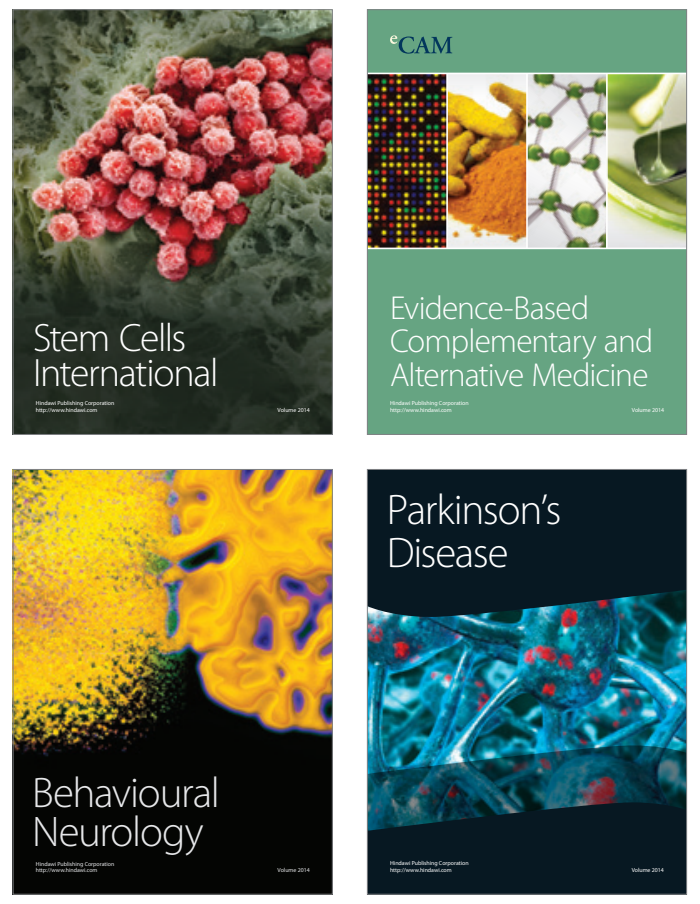
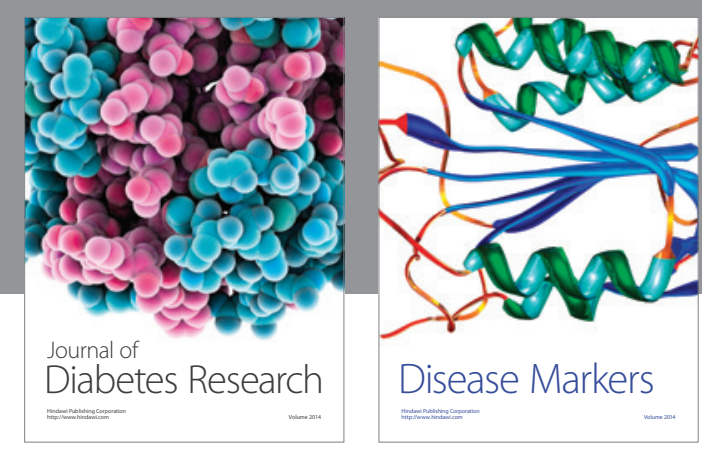

Disease Markers
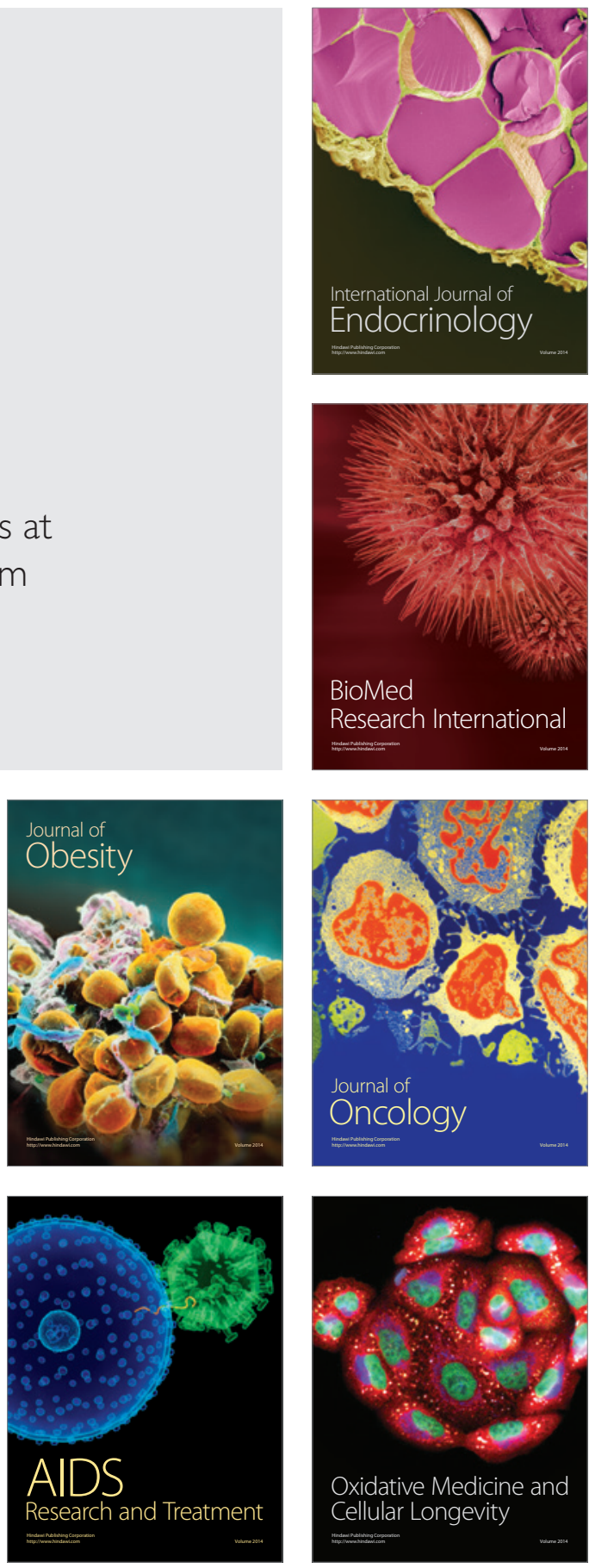